\title{
Reverse Cholesterol Transport Pathway in Experimental Chronic Renal Failure
}

\author{
Hamid Moradi ${ }^{a}$ Jun Yuan ${ }^{a}$ Zhemin $\mathrm{Ni}^{\mathrm{a}}$ Keith Norris ${ }^{\mathrm{b}}$ Nosratola D. Vaziri ${ }^{\mathrm{a}}$ \\ a Division of Nephrology and Hypertension, University of California, Irvine, Calif., b Charles Drew University, \\ Los Angeles, Calif., USA
}

\section{Key Words}

Oxidative stress $\cdot$ Atherosclerosis $\cdot$ Cardiovascular disease $\cdot$

Lipid disorders $\cdot$ Cholesterol tion despite upregulation of the efflux (LXR, $A B C A 1, A B C G 1)$ system in the aorta in CRF is largely due to upregulation of influx (SR-AI and LOX-1) pathway and LCAT deficiency.

Copyright $\odot 2009$ S. Karger AG, Basel

\begin{abstract}
Background: Chronic renal failure (CRF) causes oxidative stress, inflammation, oxidation of lipoproteins, impaired maturation of HDL and accelerated atherosclerosis. Uptake of oxidized lipoproteins by macrophages via scavenger receptors (scavenger receptor class A type I-SR-Al, and lectinlike oxidized LDL receptor - LOX-1) leads to foam cell formation and atherosclerosis. HDL mitigates atherosclerosis by retrieving surplus cholesterol via ATP binding cassette transporter $A 1$ ( $A B C A 1)$ and ABCG1 transporters whose expression is regulated by liver $X$ receptor (LXR). Free cholesterol reaching the surface of HDL is esterified by lecithin-cholesterol acyltransferase (LCAT) and sequestered in the core of $\mathrm{HDL}$, thereby maximizing cholesterol uptake. In the liver, lipid-rich HDL unloads its lipid contents via reversible binding to SR-BI while lipid-poor HDL is degraded by the holo-receptor (ATP synthase $\beta$-chain). Methods: Expression of the above molecules involved in reverse cholesterol/lipid transport was assessed in rats 8 weeks after $5 / 6$ nephrectomy (CRF) or sham operation. Results: CRF caused heavy accumulation of neutral lipids, upregulation of SR-Al, LOX-1, $L X R \alpha / \beta, A B C A 1$ and $A B C G 1$ in the aorta, reduction in $L C A T$ in the plasma and no significant change in either SR-BI or $\beta$ chain ATP synthase in the liver. Conclusions: Lipid accumula-
\end{abstract}

\section{Introduction}

Chronic renal failure (CRF) is associated with accelerated atherosclerosis and increased cardiovascular morbidity and mortality [1]. Several factors contribute to atherosclerosis and cardiovascular disease in CRF. Chief among them are oxidative stress, inflammation, hypertension and dyslipidemia. CRF-induced dyslipidemia is characterized by diminished plasma level and impaired maturation of HDL, defective clearance of triglyceriderich lipoproteins and elevated level of atherogenic lipoprotein remnants, and oxidized lipids and lipoproteins [2]. In the artery wall, oxidized or otherwise modified lipoproteins are engulfed by macrophages via scavenger receptors, a process that can lead to foam cell formation and atherosclerosis [3]. HDL plays a major role in mitigating this process by limiting lipid/lipoprotein oxidation and by retrieving surplus cholesterol for disposal in the liver, a process commonly known as reverse cholesterol transport (fig. 1) [4, 5]. In addition, HDL plays a major role in metabolism of triglyceride-rich lipoproteins by serving as an ApoC and ApoE donor for the nascent chylomicrons and VLDL, a process which is vital in metabo-

\section{KARGER}

(C) 2009 S. Karger AG, Basel

Fax +41613061234 E-Mail karger@karger.ch www.karger.com www.karger.com/ajn
N.D. Vaziri, MD, MACP

Division of Nephrology and Hypertension

UCI Medical Center, 101 The City Drive

Orange, CA 92868 (USA)

Tel. +1 714456 5142, Fax +1 714456 6034, E-Mail ndvaziri@uci.edu 
Fig. 1. Diagram of the reverse cholesterol transport pathway depicting oxidized lipoprotein influx via scavenger receptors (SR-AI and LOX-1) and free cholesterol efflux via ABCA1 and ABCG1 transporters in macrophages and resident cells in the artery wall, transfer of free cholesterol from the cell surface to the lipid-poor HDL-3, esterification of free cholesterol and translocation cholesterol ester to the core of HDL, detachment of mature HDL2 and unloading of its lipid cargo via the docking receptor SR-BI followed by the release of lipid-depleted HDL-3 for recycling or degradation by $\beta$-chain of ATP synthase.

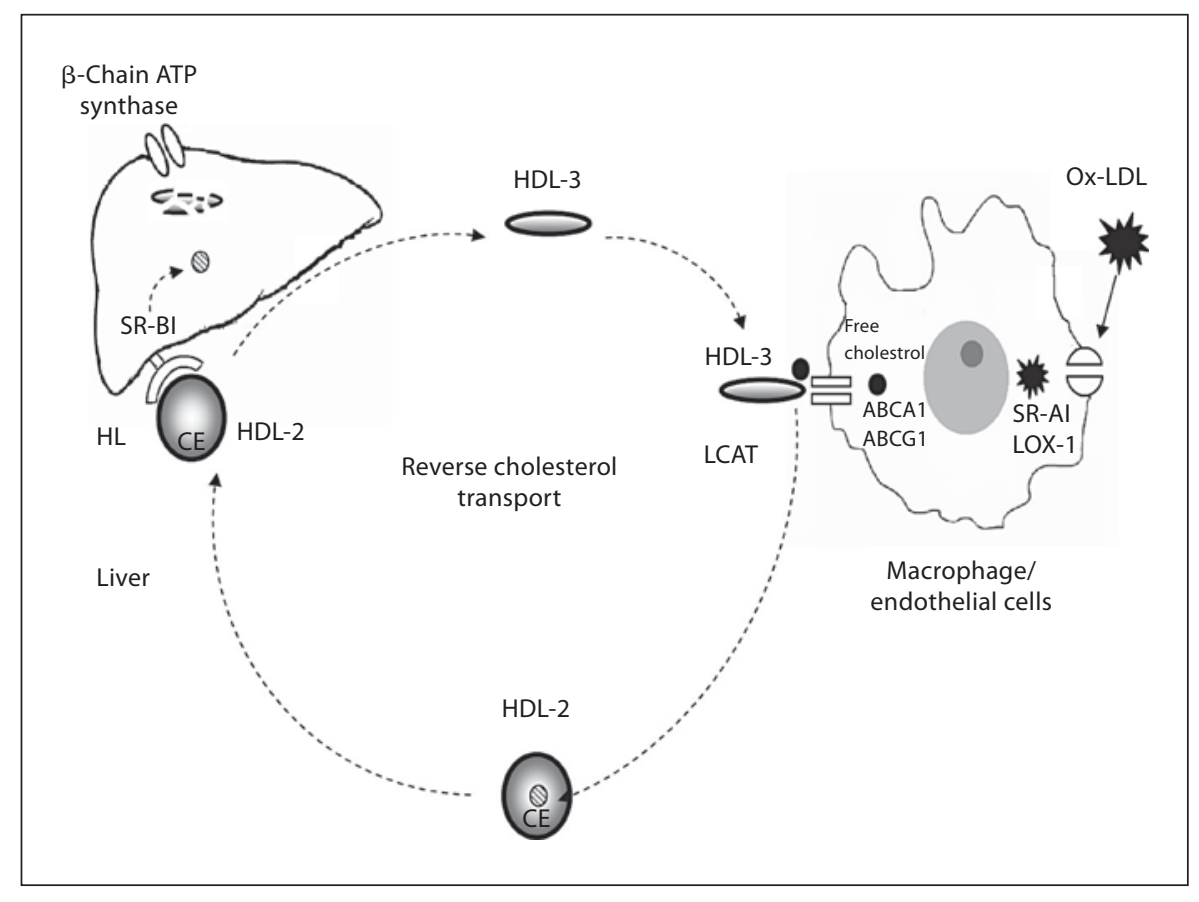

lism of these triglyceride-rich lipoproteins [2]. Moreover, HDL serves as a potent endogenous inhibitor of inflammation, platelet adhesion, and LDL oxidation [6].

HDL-mediated removal of surplus lipids from tissue macrophages requires attachment of nascent HDL to ATP binding cassette transporter A1 (ABCA1) or binding of mature HDL to ATP binding cassette transporter G1 (ABCG1) on the cell membrane [7-9]. Binding of the nascent HDL to ABCA1 triggers active transfer of phospholipids and free cholesterol from adjacent caveolae to the surface of HDL $[7,10]$. In addition, HDL binding to ABCG1 leads to further cholesterol enrichment and maturation of HDL [9]. Expression of ABCA1 and ABCG1, which are the gate keepers of cellular cholesterol efflux, is regulated by the transcription factor, liver $\mathrm{X}$ receptor $\alpha / \beta(\operatorname{LXR} \alpha / \beta)$. LXR serves as an intracellular cholesterol sensor whose activation/upregulation in response to increased intracellular free cholesterol leads to upregulation of ABCA1 and ABCG1 expressions [11].

Free cholesterol reaching the surface of HDL is rapidly esterified by lecithin-cholesterol acyltransferase (LCAT) and sequestered in the core of HDL, allowing maximal uptake of cholesterol by HDL. This process is critical for HDL maturation and efficient HDL-mediated reverse cholesterol transport $[2,12]$. Once loaded with cholesterol ester, HDL detaches from ABCA1/ABCG1 transporters and travels to the liver. In the liver, HDL forms a reversible bond with the HDL docking receptor, scavenger receptor class B type I (SR-BI), which facilitates simultaneous unloading of its cholesterol ester content, as well as hydrolysis and extraction of its fatty acid cargo by hepatic lipase. This is followed by detachment of the unloaded HDL from SR-BI and its return to the blood stream for recycling [13]. In addition to SR-BI, liver contains an endocytic HDL receptor, $\beta$-chain of ATP synthase, which binds and internalizes HDL for degradation [14]. Earlier studies have shown reduction in plasma apolipoprotein A-1 (ApoA-1) and LCAT levels and downregulations of hepatic ApoA-1 and LCAT gene expression in CRF rats [15-17] and diminished plasma LCAT activity and concentration in CRF patients $[18,19]$. These events can account for diminished plasma level and impaired maturation of HDL in advanced CRF. However, to our knowledge, the effect of CRF on lipid influx [scavenger receptor class A type I (SR-AI) and lectin-like oxidized LDL receptor (LOX-1)] and efflux (LXR, ABCA1/ABCG1) pathways in the atherosclerosis-prone conduit arteries has not been elucidated. Likewise, the effect of CRF on the liver HDL endocytic receptor, $\beta$-chain of ATP synthase, has not been investigated previously. The present study was designed to test the hypothesis that proatherosclerotic diathesis in CRF may be, in part, related to dysregulation of lipid influx and efflux pathways. 


\section{Materials and Methods}

\section{Materials}

All chemicals used in these experiments were purchased from Sigma Chemical, Co. (St. Louis, Mo., USA). Buffers and gels used in the Western blot analyses were purchased from Invitrogen (Carlsbad, Calif., USA).

\section{Animals}

Male Sprague-Dawley rats weighting 225-250 g were purchased from Harlan Sprague Dawley, Inc. (Indianapolis, Ind., USA). They were housed in a climate-controlled, light-regulated facility with 12:12 h light:dark cycles. The animals were fed regular rat chow (Purina Mills, Brentwood, Mo., USA), containing $49 \%$ carbohydrates, $24 \%$ protein, $5 \%$ fat, $7 \%$ minerals, $6 \%$ fiber and various vitamins, and water ad libitum. The animals were randomly assigned to the CRF and control groups. The animals assigned to the CRF group underwent $5 / 6$ nephrectomy by surgical resection of the upper and lower thirds of the left kidney followed by right nephrectomy 4 days later. The animals assigned to the control group were subjected to sham operation. All surgical procedures were performed under general anesthesia (Nembutal $50 \mathrm{mg} / \mathrm{kg}$ IP). Strict hemostasis and aseptic techniques were observed. The nephrectomy procedures were carried out through dorsal incisions, as described in our earlier studies [20]. Animals were maintained under the above conditions for 8 weeks. Arterial pressure was determined by tail plethysmography (Harvard Apparatus) as described in our previous studies [21]. At the end of the observation period, animals were placed in individual metabolic cages for a timed urine collection. Subsequently, they were anesthetized (Nembutal $50 \mathrm{mg} / \mathrm{kg}$, IP) and exsanguinated by cardiac puncture. Remnant aorta and liver were promptly removed, cleaned and snap frozen in liquid nitrogen. All tissues were stored at $-70^{\circ} \mathrm{C}$ until processed. All experiments were approved by the University of California Irvine institutional committee for the use and care of experimental animals.

\section{Total Tissue Protein Extraction}

Frozen tissue was homogenized in $1 \mathrm{ml}$ of $20 \mathrm{mM}$ Tris $\mathrm{HCl}$ (pH 7.5) buffer containing $2 \mathrm{mM} \mathrm{MgCl}, 0.2 \mathrm{M}$ sucrose and protease inhibitor cocktail (Sigma). The crude extract was centrifuged at $2,000 \mathrm{~g}$ at $4^{\circ} \mathrm{C}$ for $15 \mathrm{~min}$ to remove tissue debris. The supernatant was used for Western blot analyses.

\section{Membrane Protein Extraction}

Membrane proteins were extracted from frozen tissue using the protocol published by Sweet et al. [22] with a few minor modifications. Briefly, frozen tissue was homogenized in $1 \mathrm{ml}$ of $12 \mathrm{mM}$ Tris-Hepes ( $\mathrm{pH}$ 7.4) buffer containing $300 \mathrm{~mm}$ mannitol (homogenization buffer) and protease inhibitor cocktail (Sigma). The crude extract was then centrifuged at $500 \mathrm{~g}$ for $5 \mathrm{~min}$ and the supernatant was transferred to a fresh tube while the pellet was discarded. The extract was then centrifuged at $20,500 \mathrm{~g}$ for $20 \mathrm{~min}$. The pellet was then resuspeneded in fresh homogenization buffer and spun again at 20,500 $\mathrm{g}$ for another $20 \mathrm{~min}$. Subsequently, the pellet was resuspended in Tris-Hepes $\mathrm{pH} 7.4$ buffer containing 100 mM mannitol, $100 \mathrm{mM} \mathrm{KCl,} 1 \mathrm{mM} \mathrm{MgSO}_{4}$ (vesicle buffer) and protease inhibitor cocktail (Sigma). The suspension was then centrifuged at $20,500 \mathrm{~g}$ for another $20 \mathrm{~min}$ and the pellet was resuspended in the vesicle buffer and used for Western blot analysis.
Western Blot Analyses

Protein concentration was measured prior to each Western blot analysis using a BCA Protein Assay Kit purchased from Pierce Biotechnology (Rockford, Ill., USA) following the manufacturer's protocol. Aliquots containing 20-100 $\mu \mathrm{g}$ of protein were fractionated on 4-20\% Bis-Tris gels (Invitrogen, Calif., USA) at $120 \mathrm{~V}$ for $2 \mathrm{~h}$. After electrophoresis, proteins were transferred to Hybond enhanced chemiluminescence (ECL) membrane (Amersham Life Science, Arlington Heights, Ill., USA). The membrane was incubated for $1 \mathrm{~h}$ in blocking buffer $(1 \times$ Tris-buffered saline, TBS, $0.1 \%$ Tween $20,5 \%$ nonfat dry milk) and then overnight in the same buffer containing the primary antibody. Membrane was then washed four times for $5 \mathrm{~min}$ in $1 \times$ TBS, $0.1 \%$ Tween 20 before a 2 -hour incubation in blocking buffer $(1 \times$ TBS, $0.1 \%$ Tween $20,5 \%$ nonfat dry milk) plus diluted horseradish peroxidase-linked anti-mouse or rabbit IgG (Amersham Life Science). The washing procedures were repeated before the membranes were developed with chemiluminescent agents (ECL; Amersham Life Science) and subjected to autoluminography for $30 \mathrm{~s}$ to $5 \mathrm{~min}$.

\section{Total Tissue Protein Analysis}

$\mathrm{ABCA} 1$ and $\mathrm{ABCG} 1$ protein abundance was measured using a polyclonal rabbit IgG antibody (Novus Biological, Littleton, Colo., USA) at 1/1,000 dilution. Horseradish peroxidase-linked anti-rabbit IgG secondary antibody (Amersham Life Science) was used at 1/3,000 dilution. SR-AI protein abundance in the aorta was measured using a polyclonal goat IgG antibody (Novus Bilogical) at 1/2,500 dilution. Horseradish peroxidase-linked antigoat IgG secondary antibody (Abcam Inc., Cambridge, Mass., USA) was used at 1/3,000 dilution. LOX-1 protein abundance in the aorta was measured using a polyclonal rabbit antibody (Abcam Inc.) at a 1/3,000 dilution. Horseradish peroxidase-linked anti-rabbit IgG secondary antibody (Amersham Life Science) was used at $1 / 3,000$ dilution. $\operatorname{LXR} \alpha / \beta$ protein abundance was measured using a rabbit polyclonal antibody (Santa Cruz Biotechnology, Santa Cruz, Calif., USA) at 1/2,500 dilution. Horseradish peroxidase-linked anti-mouse IgG secondary antibody (Amersham Life Science) was used at 1/3,000 dilution. SR-BI protein abundance was measured using a polyclonal rabbit IgG antibody (Novus Biological) at 1/4,000 dilution. Horseradish peroxidaselinked anti-rabbit IgG secondary antibody (Amersham Life Science) was used at 1/3,000 dilution.

\section{Membrane Protein Analysis}

$\beta$-Chain ATP synthase protein abundance in the liver tissue was measured using a mouse monoclonal antibody (BD Biosciences, San Jose, Calif., USA) at a 1/3,000 dilution. Horseradish peroxidase-linked anti-mouse IgG secondary antibody (Amersham Life Science) was used at 1/3,000 dilution.

\section{Miscellaneous Measurements}

A colorimetric assay was used to measure serum and urine creatinine and blood urea nitrogen concentration using a kit obtained from Bioassay Systems (Hayward, Calif., USA) following the manufacturer's protocol. Plasma total cholesterol and triglycerides were measured by a colorimetric assay (Thermo Electron Inc., Waltham, Mass., USA) following the manufacturer's protocol and using a SpectraMax M5 plate reader (Molecular Devices, Sunnyvale, Calif., USA). HDL cholesterol was extracted using 


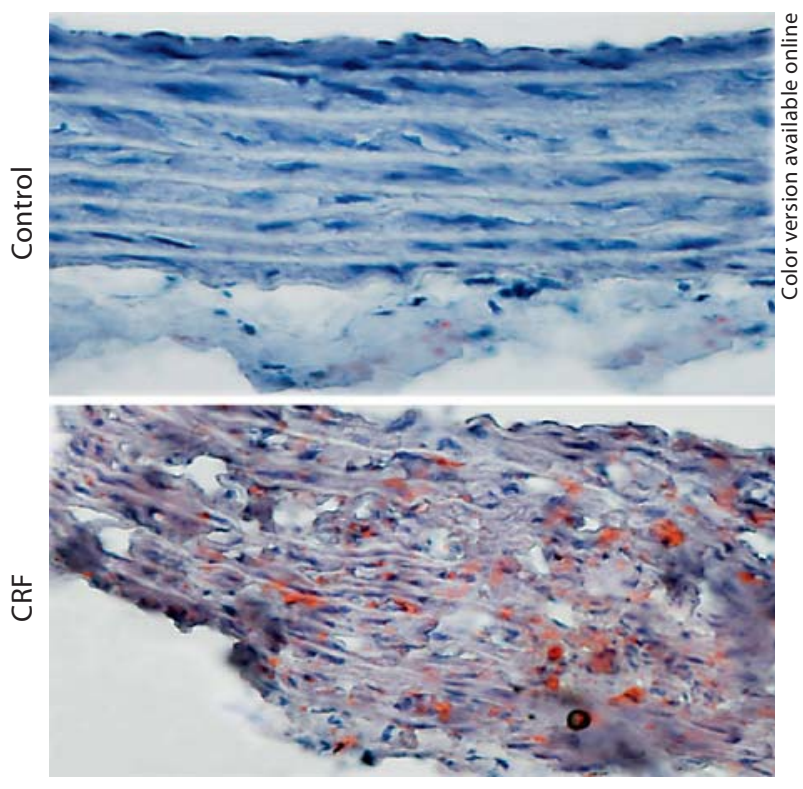

Fig. 2. Representative photomicrographs of the Oil Red O-stained aorta demonstrating marked accumulation of neutral lipids coupled with significant cellular infiltration and altered arterial wall architecture, consistent with early plaque formation in the CRF group. In contrast, little lipid staining was found and the aorta wall structure was intact in the normal control rats.

HDL Magnetic Bead Reagent (Polymedco Inc., Chicago, Ill., USA). Two hundred microliters of sera were incubated with $40 \mu \mathrm{l}$ the magnetic bead reagent at room temperature for $5 \mathrm{~min}$ with gentle mixing. The mixture was placed on the magnetic particle concentrator for $3 \mathrm{~min}$ and the HDL-containing supernatant was removed. The HDL cholesterol content was measured by a colorimetric assay (Thermo Electron Inc., Waltham, Mass., USA) using a SpectraMax M5 plate reader (Molecular Devices). Urine protein was measured using a rat urinary protein assay kit (Chondrex, Inc., Redmond, Wash., USA) following the manufacturer's protocol. Plasma LCAT concentration was measured by ELISA as described in our earlier studies [23].

\section{Tissue Lipid Staining}

After euthanizing the animals, thoracic aorta was rapidly removed and immersed in $4 \%$ PFA/PBS (at $4^{\circ} \mathrm{C}$ ) overnight. Subsequently, the tissue was cryoprotected in $30 \%$ sucrose at $4^{\circ} \mathrm{C}$ and then frozen using liquid nitrogen. Frozen sections were then cut using Leica CM 1900 UV (Leica, Solms, Germany) at $10 \mu \mathrm{m}$. Each section was air dried for $1 \mathrm{~h}$ and fixed in $10 \%$ formalin for $10 \mathrm{~min}$. Subsequently, the tissue was rinsed with distilled water and the sections were stained with Oil Red O (Sigma Aldrich, St. Louis, Mo., USA) per manufacturer's protocol.

\section{Data Analysis}

Student's t tests were used in statistical evaluation of the data, which are presented as mean \pm SE. A p value $<0.05$ was considered significant.
Table 1. Body weight, serum urea, creatinine, triglyceride and total cholesterol/HDL cholesterol ratio and urine protein excretion normalized against creatinine in the CRF and control groups (6 animals in each group)

\begin{tabular}{lcc}
\hline & Control & CRF \\
\hline Body weight, g & $623 \pm 26.3$ & $493 \pm 26.4^{* *}$ \\
Serum urea, $\mathrm{mg} / \mathrm{dl}$ & $23.8 \pm 1.7$ & $60.5 \pm 4.6^{* * *}$ \\
Serum creatinine, mg/dl & $0.38 \pm 0.12$ & $1.69 \pm 0.33^{* *}$ \\
Triglyceride, $\mathrm{mg} / \mathrm{dl}$ & $46.6 \pm 4.5$ & $166 \pm 17$ \\
Total cholesterol/HDL ratio & $2.7 \pm 0.3$ & $3.7 \pm 0.5^{*}$ \\
Urine protein/creatinine ratio & $0.4 \pm 0.18$ & $5.45 \pm 2^{* *}$ \\
\hline
\end{tabular}

${ }^{*} \mathrm{p}<0.05,{ }^{* *} \mathrm{p}<0.01,{ }^{* * *} \mathrm{p}<0.001$

\section{Results}

\section{General Data}

Data are summarized in table 1 . As expected, the CRF group showed a significant increase in arterial pressure, serum creatinine concentration and urinary protein excretion as compared with the corresponding values found in the sham-operated control rats. Plasma total cholesterol and triglyceride concentrations and total cholesterol to HDL cholesterol concentration ratio were significantly elevated in CRF compared with the sham-operated control group.

\section{Tissue Lipid Contents}

The aorta of the CRF animals showed patchy areas of wall thickening and yellowish discoloration. In contrast, the control aorta showed smooth luminal surface and uniform wall thickness. Oil Red O staining of the frozen aorta revealed marked accumulation of neutral lipids in the aorta in the CRF group. This was accompanied by significant cellular infiltration and alteration of the arterial wall architecture consistent with early plaque formation. In contrast, little lipid staining was found and the wall structure was intact in the aorta of normal control rats (fig. 2).

\section{SR-AI and LOX-1 Data}

Data are depicted in figure 3. Accumulation of lipids was accompanied by a marked elevation of SR-AI protein abundance in the thoracic aorta of the CRF rats. Likewise, LOX-1 protein abundance was markedly increased in the thoracic aorta of the CRF group. These findings demonstrate upregulation of lipid influx pathway in the arterial wall in the CRF animals. 
Fig. 3. Representative Western blots and group data depicting protein abundance of the LOX-1 (a) and SR-AI (b) in the aorta tissues of the CRF and CTL rats ( 6 animals in each group). ${ }^{*} \mathrm{p}<0.05,{ }^{*} \mathrm{p}<0.01$.
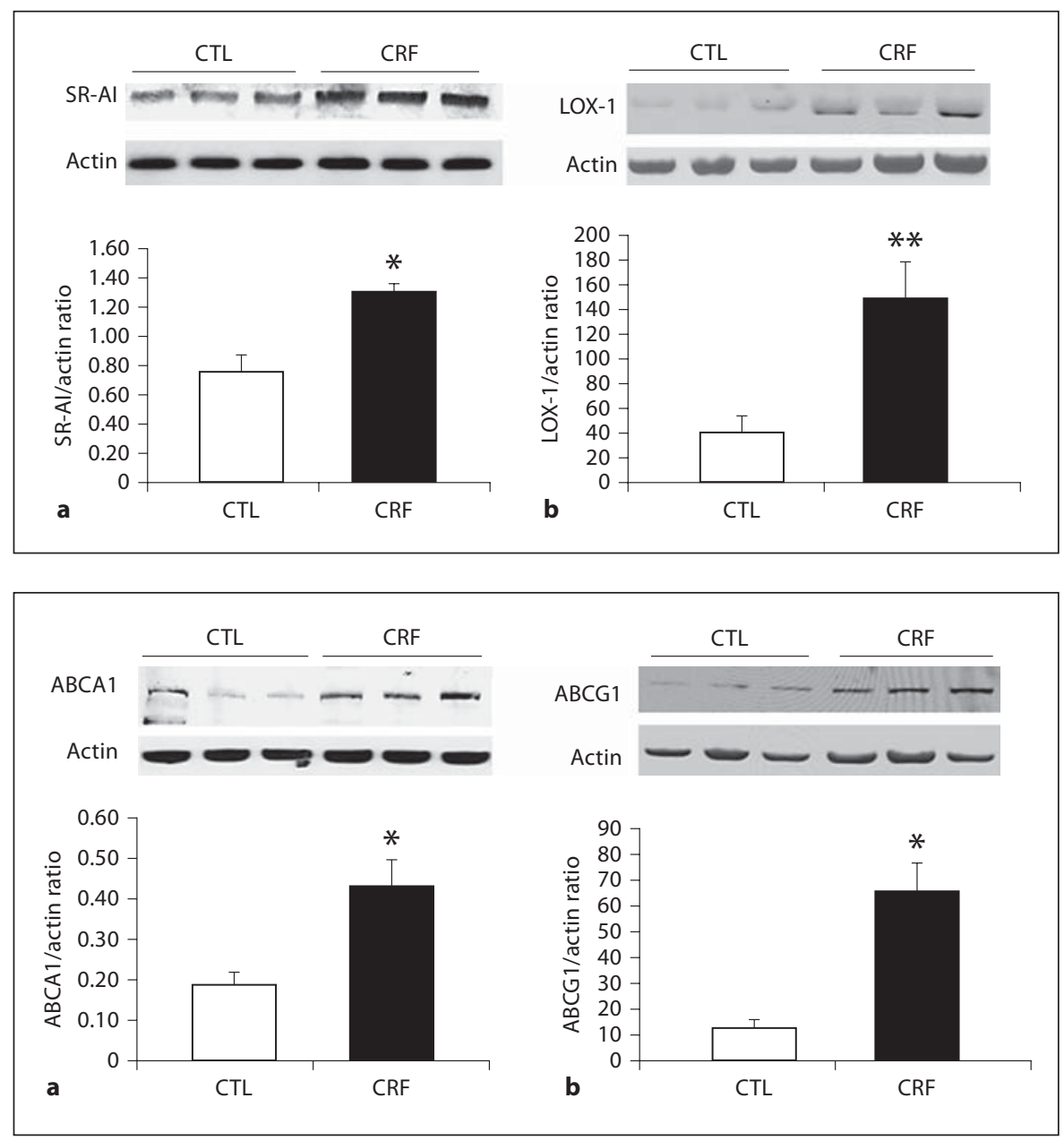

Fig. 4. Representative Western blots and group data depicting protein abundance of the aorta tissue ABCA1 (a) and ABCG1 (b) in the CRF and CTL groups ( 6 animals in each group). ${ }^{*} \mathrm{p}<0.05$. that found in the control animals. Given the critical role of LCAT in promoting HDL-mediated cholesterol uptake, its deficiency is, in part, responsible for accumulation of lipids in the artery wall despite upregulation of the efflux pathway in vascular tissues in CRF.

\section{Hepatic SR-BI and $\beta$-Chain ATP Synthase Data}

Data regarding hepatic SR-BI and $\beta$-chain ATP synthase are illustrated in figure 7 . In confirmation of our earlier studies [24], SR-BI abundance in the liver tissue was unchanged in CRF rats employed in the present study. Likewise, protein abundance of the HDL endocytic receptor ( $\beta$-chain ATP synthase) in the membrane fraction of the liver of the CRF rats was comparable to that found in the control rats. These findings tend to exclude possible reduction of hepatic HDL receptor system as a major cause of impaired reverse cholesterol/lipid transport in CRF. 
5

Fig. 5. Representative Western blots and group data depicting protein abundance of the aorta tissue LXR $\alpha / \beta$ in the CRF and CTL groups ( 6 animals in each group). ** $\mathrm{p}<0.01$.

Fig. 6. Bar graph depicting plasma LCAT concentration in CRF and CTL rats (6 animals in each group). ${ }^{* *} \mathrm{p}<0.01$.

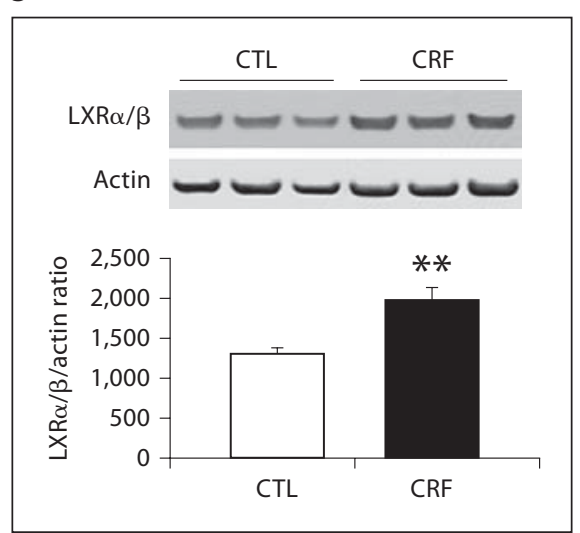

6
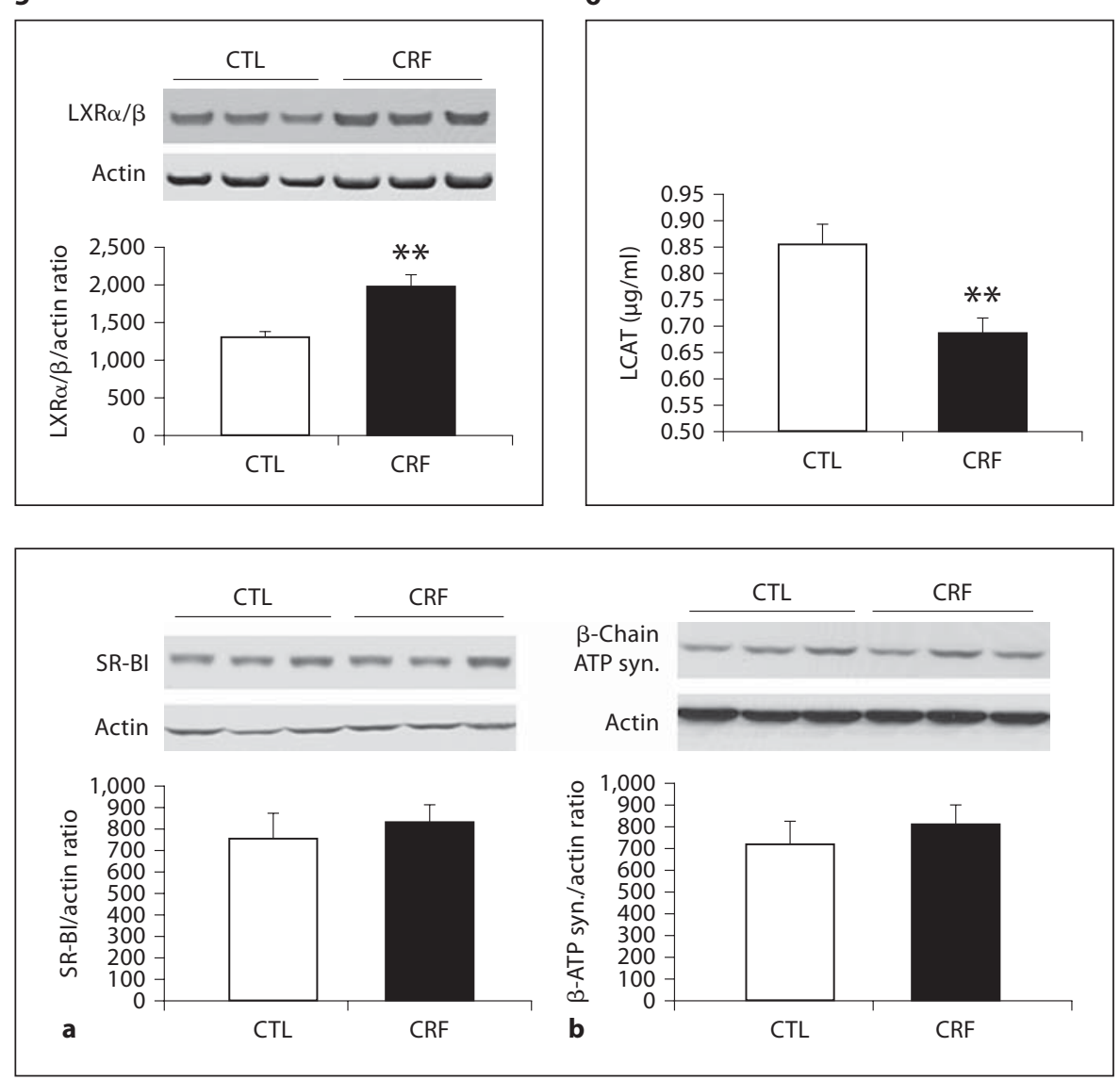

Fig. 7. Representative Western blots and group data depicting protein abundance of the liver tissue SR-BI (a) and $\beta$-chain ATP synthase (b) in the CRF and CTL groups (6 animals in each group). terol concentration, expression of scavenger receptors including SR-AI is not regulated by the intracellular cholesterol contents [33]. Consequently, irrepressible uptake of modified lipoproteins via these receptors can result in foam cell formation, tissue lipid accumulation and atherosclerosis [28, 34].

ABCA1 and ABCG1 transporters are the gatekeepers of reverse cholesterol transport pathway. In the peripheral tissues, ABCA1 and ABCG1 mediate transfer of cellular cholesterol and phospholipids to lipid-poor HDL and mature HDL, respectively [7-9]. Expression of ABCA1, ABCG1 and a number of other genes involved in cholesterol absorption, efflux, transport, and excretion is regulated by $L X R \alpha / \beta$ which serves as an intracellular cholesterol sensor [11]. The CRF rats employed in the present study exhibited marked upregulation of ABCA1, ABCG1 and $L X R \alpha / \beta$ in the aorta. Upregulation of ABCA1 and ABCG1, which are the primary pathways of cholesterol efflux and activation of their master regulator, LXR, point to the cellular response to increased cholesterol burden in the aorta. It is of note that oxidative 
modification of HDL can interfere with its binding to ABCA1 transporter [35]. In this context, HDL from patients with end-stage CRF has been recently shown to be pro-oxidant, reflecting its oxidative modification [18] The CRF-induced oxidative modification of HDL can, therefore, contribute to lipid accumulation in the artery wall by limiting its ability to effectively bind to ABCA1 transporter in order to mediate reverse cholesterol transport.

Plasma LCAT level was significantly reduced in our $\mathrm{CRF}$ rats. Free cholesterol reaching the surface of HDL is esterified by LCAT and is sequestered in the core of HDL. This event is critical for maximal cholesterol uptake by and maturation of HDL. Thus, LCAT plays an important part in HDL-mediated cholesterol uptake from the extrahepatic tissues and, as such, serves as a main determinant of HDL maturation and plasma HDL cholesterol level. It is of note that plasma LCAT activity is consistently diminished in patients with ESRD $[2,18,19]$. In addition, plasma LCAT activity, plasma LCAT concentration and hepatic LCAT gene expression are markedly reduced in uremic rats [15-17]. Thus, renal insufficiency results in LCAT deficiency which contributes to reduced HDL cholesterol, impaired HDL maturation and the associated cardiovascular complications.

SR-BI serves as the docking receptor for disposal of HDL's cholesterol and triglyceride cargo in the liver and the return of the lipid-depleted HDL for recycling [13]. Heavy glomerular proteinuria has been shown to significantly reduce hepatic SR-BI protein expression in experimental animals [36]. In contrast, CRF per se, without heavy proteinuria, does not significantly change SR-BI
mRNA or protein abundance in the liver [24]. In agreement with our previous findings, the CRF rats employed in the present study exhibited normal levels of SR-BI in the liver tissue.

The mitochondrial $\beta$-chain subunit of ATP synthase has been identified on the plasma membrane of hepatocytes where it serves as a receptor which can bind and internalize ApoA-1 and lipid-poor HDL, and as such participates in their catabolism [14, 37]. Given the important role of this receptor in HDL metabolism, we determined its membrane abundance in the liver of CRF and control rats. We found no significant difference in the hepatic tissue abundance of this receptor between the CRF and the control rats. These observations appear to exclude possible changes in hepatic HDL receptor system as a major cause of impaired reverse cholesterol/lipid transport in CRF.

In conclusion, despite normality of hepatic HDL receptors and compensatory upregulation of the lipid efflux (LXR, ABCA1, ABCG1) system, CRF resulted in heavy lipid accumulation in the aorta. This was associated with and largely due to upregulation of the lipid influx (SR-AI and LOX-1) pathway and LCAT deficiency, events which support lipid influx and limit HDL-mediated retrieval of cellular lipids.

\section{Acknowledgement}

This study was in part supported by the NIH grant, 5-U54RR0119234.

\section{References}

1 Go AS, Chertow GM, Fan D, McCulloch CE, Hsu CY: Chronic kidney disease and the risks of death, cardiovascular events, and hospitalization. N Engl J Med 2004;351: 1296-1305.

2 Vaziri ND: Dyslipidemia of chronic renal failure: the nature, mechanisms and potential consequences. Am J Physiol Renal Physiol 2006;290:262-272.

>3 Gough PJ, Greaves DR, Suzuki H, Hakkinen T, Hiltunen MO, Turunen M, Herttuala SY, Kodama T, Gordon S: Analysis of macrophage scavenger receptor (SR-A) expression in human aortic atherosclerotic lesions. Arterioscler Thromb Vasc Biol 1999;19:461471 .
-4 Fielding CJ, Fielding PE: Molecular physiology of reverse cholesterol transport. J Lipid Res 1995;36:211-228.

$\checkmark 5$ Genest J Jr, Marcil M, Denis M, Yu L: High density lipoproteins in health and in disease. J Investig Med 1999;47:31-42.

-6 Navab M, Berliner JA, Subbanagounder G, Hama S, Lusis AJ, Castellani LW, Reddy S, Shih D, Shi W, Watson AD, Van Lenten BJ, Vora D, Fogelman AM: HDL and the inflammatory response induced by LDL-derived oxidized phospholipids. Arterioscler Thromb Vasc Biol 2001;21:481-488.

$\checkmark 7$ Fielding CJ, Fielding PE: Cellular cholesterol efflux. Biochim Biophys Acta 2001;1533: 175-189.
8 Lawn RM, Wade DP, Garvin MR, Wang X, Schwartz K, Porter JG, SeilhamerJJ, Vaughan AM, Oram JF: The Tangier disease gene product $\mathrm{ABC} 1$ controls the cellular apolipoprotein-mediated lipid removal pathway. J Clin Invest 1999;104:R25-R31.

9 Oram JF, Vaughan AM: ATP-binding cassette cholesterol transporters and cardiovascular disease. Circ Res 2006;99:1031-1043.

10 Neufeld EB, Remaley AT, Demosky SJ Jr, Stonik JA, Cooney AM, Comly M, Dwyer NK, Zhang M, Blanchette-Mackie J, Santamarina-Fojo S, Brewer HB Jr: Cellular localization and trafficking of the human ABCA1 transporter. J Biol Chem 2001;276: 27584-27590. 
11 Tontonoz P, Mangelsdorf DJ: Liver X receptor signaling pathways in cardiovascular disease. Mol Endocrinol 2003;17:985-993.

12 Glomset JA: The plasma lecithins:cholesterol acyltransferase reaction. J Lipid Res 1968;9: 155-167.

13 Acton S, Rigotti A, Landschulz KT, Xu S, Hobbs $\mathrm{HH}$, Krieger M: Identification of scavenger receptor SR-BI as a high density lipoprotein receptor. Science 1996;271:518520.

14 Martinez LO, Jacquet S, Esteve JP, Rolland C, Cabezón E, Champagne E, Pineau T, Georgeaud V, Walker JE, Tercé F, Collet X, Perret B, Barbaras R: Ectopic beta-chain of ATP synthase is an apolipoprotein A-I receptor in hepatic HDL endocytosis. Nature 2003;421: 75-79.

15 Liang K, Kim C, Vaziri ND: HMG-CoA reductase inhibition reverses LCAT and LDL receptor deficiencies and improves HDL in rats with chronic renal failure. Am J Physiol Renal Physiol 2005;288:F539-F544.

-16 Vaziri ND, Liang K, Parks JS: Downregulation of lecithin:cholesterol acyltransferase (LCAT) in chronic renal failure. Kidney Int 2001;59:2192-2196.

- 17 Vaziri ND, Sato T, Liang K: Molecular mechanism of altered cholesterol metabolism in focal glomerulosclerosis. Kidney Int 2003; 63:1756-1763.

- 18 Moradi H, Pahl MV, Elahimehr R, Vaziri ND: Impaired antioxidant activity of high density lipoprotein in chronic kidney disease. Transl Res 2009;153:77-85.

19 Shoji T, Nishizawa Y, Nishitani H, Billheimer JT, Sturley SL: Impaired metabolism of high density lipoprotein in uremic patients. Kidney Int 1992;41:1653-1661.

20 Vaziri ND, Ni Z, Wang XQ, Oveisi F, Zhou $\mathrm{XJ}$ : Downregulation of nitric oxide synthase in chronic renal insufficiency: role of excess PTH. Am J Physiol Renal Physiol 1998;274: F642-F649.
21 Gonick HC, Ding Y, Bondy SC, Ni Z, Vaziri ND: Lead-induced hypertension. Interplay of nitric oxide and reactive oxygen species. Hypertension 1997;30:1487-1492.

22 Sweet DH, Miller DS, Pritchard JB: Basolateral localization of organic cation transporter 2 in intact renal proximal tubules. Am J Physiol Renal Physiol 2000;279:F826-F834.

23 Vaziri ND, Liang K, Park JS: Acquired lecithin-cholesterol acyltransferase deficiency in nephrotic syndrome. Am J Physiol Renal Physiol 2001;280:F823-F828.

24 Vaziri ND, Deng G, Liang K: Hepatic HDL receptor, SR-B1 and Apo A-I expression in chronic renal failure. Nephrol Dial Transplant 1999;14:1462-1466.

25 Chen M, Masaki T, Sawamura T: LOX-1, the receptor for oxidized low-density lipoprotein identified from endothelial cells: implications in endothelial dysfunction and atherosclerosis. Pharmacol Ther 2002;95:89100.

26 Cominacini L, Pasini AF, Garbin U, Davoli A, Tosetti ML, Campagnola M, Rigoni A, Pastorino AM, Lo Cascio V, Sawamura T: Oxidized low density lipoprotein (ox-LDL) binding to ox-LDL receptor-1 in endothelial cells induces the activation of NF-kappaB through an increased production of intracellular reactive oxygen species. J Biol Chem 2000;275:12633-12638.

27 Cominacini L, Rigoni A, Pasini AF, Garbin U, Davoli A, Campagnola M, Pastorino AM, Lo Cascio V, Sawamura T: The binding of oxidized low density lipoprotein (ox-LDL) to ox-LDL receptor-1 reduces the intracellular concentration of nitric oxide in endothelial cells through an increased production of superoxide. J Biol Chem 2001;276:1375013755.

28 Moore KJ, Freeman MW: Scavenger receptors in atherosclerosis: beyond lipid uptake. Arterioscler Thromb Vasc Biol 2006;26: 1702-1711.
29 Himmelfarb J, Stenvinkel P, Ikizler TA, Hakim R: The elephant in uremia: oxidant stress as a unifying concept of cardiovascular disease in uremia. Kidney Int 2002;62: 1524-1538.

30 Vaziri ND: Oxidative stress in chronic renal failure: the nature, mechanism and consequences. Semin Nephrol 2004;24:469-473.

31 Vaziri ND, Bai Y, Ni Z, Quiroz Y, RodriguezIturbe $\mathrm{B}$ : Intra-renal angiotensin II/AT 1 receptor, oxidative stress, inflammation and progressive injury in renal mass reduction. J Pharmacol Exp Ther 2007;323:85-93.

32 Brown MS, Goldstein JL: The SREBP pathway: regulation of cholesterol metabolism by proteolysis of a membrane-bound transcription factor. Cell 1997;89:331-340.

$>33$ De Winther M, Hofker M: Scavenging new insights into atherogenesis. J Clin Invest 2000;105:1039-1041.

>34 Mehta JL, Chen J, Hermonat PL, Romeo F, Novelli G: Lectin-like, oxidized low-density lipoprotein receptor-1 (LOX-1): a critical player in the development of atherosclerosis and related disorders. Cardiovasc Res 2006; 69:36-45.

35 Shao B, Oda MN, Oram JF, Heinecke JW: Myeloperoxidase: an inflammatory enzyme for generating dysfunctional high density lipoprotein. Curr Opin Cardiol 2006;21:322328.

36 Liang K, Vaziri ND: Downregulation of hepatic high-density lipoprotein receptor, SRB1 in nephrotic syndrome. Kidney Int 1999; 56:621-626

-37 Fabre AC, Vantourout P, Champagne E, Tercé F, Rolland C, Perret B, Collet X, Barbaras $\mathrm{R}$, Martinez LO: Cell surface adenylate kinase activity regulates the F (1)-ATPase/P2Y (13)-mediated HDL endocytosis pathway on human hepatocytes. Cell Mol Life Sci 2006; 63:2829-2837. 